\title{
Technology-Mediated Language Training: Developing and Assessing a Module for a Blended Curriculum for Newcomers
}

\author{
Gillian McLellan \\ Carleton University \\ Eva Kartchava \\ Carleton University \\ Michael Rodgers \\ Carleton University
}

\begin{abstract}
Newcomers to Canada with low proficiency in English or French often face challenges in the workforce (Kustec, 2012). While language classes provide workplace language training, not all newcomers are able to attend face-to-face classes (Shaffir \& Satzewich, 2010), suggesting a need for outside the classroom, occupation-specific language training. The use of technology has been shown to be advantageous for second language (L2) learning (Stockwell, 2007), especially when used outside the classroom (i.e., mobile-assisted language learning), as mobile technology affords learners greater control and flexibility over their own learning (Yang, 2013). This paper reports on a study investigating the development of a blended curriculum for L2 learners employed in customer service. A technologymediated module was designed and developed within a task-based language teaching framework to provide workplace-linguistic support on mobile devices, enabling learners to access the language instruction they needed, when they needed it. The module contents and usability were assessed by high-beginner English proficiency newcomers employed in customer service $(n=4)$ and their volunteer teachers $(n=4)$. Results confirm the overall benefits of using language learning technology in providing instruction that meets participant language needs, ensuring opportunities for individualized training. Implications for designing, implementing, and researching technology-mediated modules are discussed.
\end{abstract}

\section{Résumé}

Les nouveaux arrivants au Canada ayant une faible maitrise de l'anglais ou du français sont souvent confrontés à des difficultés sur le marché du travail (Kustec, 2012). Bien que les cours de langue offrent une formation linguistique en milieu de travail, les nouveaux arrivants ne sont pas tous en mesure d'assister à des cours en personne (Shaffir et Satzewich, 2010), ce qui suggère un besoin de formation linguistique en dehors de la salle de classe et spécifique à la profession. L'utilisation de la technologie s'est avérée avantageuse pour l'apprentissage d'une langue seconde (L2) (Stockwell, 2007), en particulier lorsqu'elle est utilisée en dehors de la salle de classe (c'est-à-dire l'apprentissage des langues assisté par le mobile), car la technologie mobile offre aux apprenants un plus grand contrôle et une plus grande flexibilité sur leur propre apprentissage (Yang, 2013). Cet article rend compte d'une étude portant sur le développement d'un programme d'études mixte pour les apprenants de 
L2 employés dans le service à la clientèle. Un module à médiation technologique a été conçu et développé dans un cadre d'enseignement des langues basé sur les tâches afin de fournir un soutien linguistique sur le lieu de travail sur des appareils mobiles, permettant aux apprenants d'accéder à l'enseignement linguistique dont ils ont besoin, quand ils en ont besoin. Le contenu et la convivialité du module ont été évalués par des nouveaux arrivants ayant des compétences en anglais de niveau débutant élevé et employés dans un service clientèle $(n=4)$ et par leurs enseignants bénévoles $(n=4)$. Les résultats confirment les avantages généraux de l'utilisation de la technologie d'apprentissage des langues pour fournir un enseignement qui répond aux besoins linguistiques des participants, en assurant des possibilités de formation individualisée. Les implications pour la conception, la mise en œuvre et la recherche de modules médiatisés par la technologie sont discutées.

\section{Technology-Mediated Language Training: Developing and Assessing a Module for a Blended Curriculum for Newcomers}

When asked about priorities upon coming to Canada, newcomers have identified employment as their number one priority (Kustec, 2012). However, newcomers who are not proficient in one of the country's official languages often face challenges in the Canadian workforce, suggesting a need for L2 training (Murphy, 2010). And while workplace language is often included in L2 classroom curricula, these face-to-face classes are either not always accessible to L2 learners or do not adequately meet the specificity of the language used in the workplace. In terms of accessibility of face-to-face language classes, Shaffir and Satzewich (2010) suggest that challenges such as maintaining employment and limited access to childcare often prevent some learners from being able to consistently attend language classes. They also note that newcomers have expressed a desire for more language training that addresses employment-specific skills.

In order to mitigate employment challenges, a number of community employment support programs have been developed to aid Canadian newcomers by assisting them with finding and maintaining employment (Immigration, Refugees and Citizenship Canada [IRCC] 2019). While some of the programs provide career-planning services, often accompanied by face-to-face occupation-specific language training classes (Ontario Council of Agencies Serving Immigrants, 2017), other programs engender networking opportunities and employment partnerships alongside language training that is either offered face-to-face or using online language learning options (Government of Saskatchewan, 2019; S.U.C.C.E.S.S., 2019). One such program is the focus of this investigation. As part of this program, newcomers are paired with an employer in various sectors such as hospitality, trades, and customer service, and are also provided with access to some language training. Newcomers are matched with a volunteer teacher who meets with them one-on-one and face-to-face on a weekly basis for three hours. The volunteer teacher determines what materials are to be used during these sessions, but the predominant focus is workplace language.

The study discussed in this paper was done in partnership with this program and is focused on providing language support for newcomers working in the customer service sector. While this program does already provide some workplace language training, a need for additional outside the classroom language training (i.e., using technology) was identified due to the learners' limited availability to attend regularly scheduled, face-to- 
face classes. As such, it was determined that more occupation-specific (i.e., customer service) language training that addresses the specific needs of this group of learners outside the classroom using an online platform was needed. Specifically, this additional training was provided through the development of an online program, one unit of which is described here. It should be noted that this language training is not intended to replace existing face-to-face instruction with the volunteer teachers but is instead designed to augment and support the existing training as part of a blended curriculum (i.e., a curriculum that combines face-to-face and online learning). The current face-to-face instruction with volunteer teachers provides opportunities for learners to interact with native speakers and to ask questions and express their needs (Blake et al., 2008). However, this alone does not address the learners who need the flexibility and adaptability that mobile learning affords, including anytime-anywhere access.

\section{Literature Review}

\section{Computer-Assisted Language Learning}

Language learning technology is becoming increasingly integrated into the English as a second language (ESL) classroom in a variety of ways, due to continuous technological advancements (Lee \& Egbert, 2016). As such, there have been significant increases in the use of language learning technology over the last 30 years (Farr \& Murray, 2016). This type of language learning technology is commonly referred to as computerassisted language learning (CALL; Farr \& Murray, 2016). With the development of cell phones and tablets, another increasingly common term is mobile-assisted language learning (MALL), which refers to technology used via mobile devices (Godwin-Jones, 2011; Yang, 2013). In the context of this study, CALL is used to refer to a broader category of technology-mediated language learning, with MALL being a subset of CALL.

When effectively applied, CALL is thought to increase the rate of learning and make learning more efficient (Blake, 2013). Blake found that the quality of online learning was similar to that of face-to-face learning, but that use of CALL increased the rate of learning. The use of CALL enabled learners to access learning resources more frequently, thus providing learners with additional opportunities for learning. Furthermore, applying CALL provides learners with more opportunities for engaging in an L2 (Chappelle, 2005) and more opportunities for learners to receive input due to the use of audio and other multimedia tools (O'Bryan \& Hegelheimer, 2007). It is often applied in a manner that targets the four linguistic skills of reading, writing, listening, and speaking (Levy, 2009). In a review of existing literature, Stockwell (2007) concludes that the majority of CALL research has been concerned with reading and writing skills, followed by listening, with speaking receiving the least focus. By examining language skills and areas, it can be seen

how CALL has been used to enhance various aspects of L2 acquisition and how it could be employed to design completely online modules (including the module reported on here) that assist learners in their language learning efforts.

Learner and teacher perceptions of CALL have also been found to influence its use (Plonsky \& Zeigler, 2016). Insight can be gained by examining teacher and student perceptions of technology, including how to implement successfully the technology in an L2 context (Egbert et al., 2002). Exploring this can help identify obstacles that prevent 
teachers and students from using technology (Plonsky \& Zeigler, 2016). Furthermore, the usability of the software employed has been considered to directly correlate with both learner and teacher perceptions (Egbert et al., 2002; Kim, 2008; Lasagabaster \& Sierra, 2010). Software that is more challenging or that requires extensive training to use is often perceived as frustrating and is reported to be less likely to be used by teachers (Egbert et al., 2002), demonstrating the importance of selecting software that is easy to use. Furthermore, a student's frequency of use of a specific technology has been connected to the student's level of familiarity and the ease with which the technology can be used (Lasagabaster \& Sierra, 2010).

\section{Mobile-Assisted Language Learning}

The use of MALL has resulted in the development of technology that targets language relevant to specific (non-classroom) environments, including the workforce, with positive results. Ally et al. (2007) found that student perceptions of mobile-based workplace language training were positive. MALL has also been praised for its flexibility of use, including use outside the classroom (Yang, 2013). Students reported that the flexibility and availability of mobile language learning technology made them more likely to practice their English outside of the classroom (Godwin-Jones, 2011). Kukulska-Hulme and Shield (2008) also found this to be the case, a conclusion that was influenced by the fact that a significant number of students reported having access to a personal cell phone.

Stockwell (2010) observed that the convenience of mobile technology was advantageous since many students would use technology in what he refers to as "dead time" (p. 9). In other words, students were using technology at times where they were waiting for something (e.g., an appointment) or commuting. This enabled students to more easily choose when they would like to practice their language skills and easier integration of language practice into their daily lives. The use of MALL has been shown to provide learners with greater control over their own learning and to help encourage learner autonomy (Guichon \& McLornan, 2008; Schwienhorst, 2008).

Kim and Kwon (2012) have also found the use of MALL to be effective in extending learning opportunities to outside the classroom. They note the importance of MALL material developers having a thorough understanding of the technological capabilities of the given software and learner needs. This knowledge can guide content, design and the application of a pedagogical framework. While various designs and pedagogical frameworks have been applied with MALL, there is increasing interest in applying a task-based framework, as doing so has been found to be advantageous (Lamb, 2004). The application of a task-based framework with CALL or MALL has been termed "technology-mediated task-based language teaching" (González-Lloret \& Ortega, 2014)

\section{Technology-Mediated Task-Based Language Teaching}

Task-based language teaching (TBLT) is a pedagogical approach that provides learners with the opportunity to use the target language authentically (e.g., English for the workplace) by completing real-life tasks (Douglas \& Kim, 2014; Ellis, 2003). TBLT has been regarded by some as more effective than other types of teaching due to its purposeful and outcome-driven nature that encourages meaningful communication (Plews \& Zhao, 
2010). Long (2016), in particular, argues that the meaningful nature of task-based instruction causes learner knowledge to be more durable and impactful due to it having more depth than other types of teaching. The authenticity of tasks and their connection to the real world are thought to lead to better transfer of linguistic knowledge outside the classroom.

In terms of implementing tasks, Ziegler (2016) notes that when applying TBLT in the context of CALL, the definition of a task may have to be expanded upon in order to capitalize on the capabilities of the given software. However, even if the task is presented in a non-traditional format, certain principles regarding task structure are still applied, such as first preparing learners for the task (e.g., through contextualization [Beglar \& Hunt, 2002]) and then progressively increasing the cognitive demand on learners by making the tasks increasingly challenging while providing learners opportunities for language practice.

Hampel and Hauck (2004) found that the use of technology-mediated TBLT allows for more opportunities for individualized learning. Technology-mediated TBLT takes the underlying principles of TBLT and integrates them into the use of CALL to promote engaged learning (González-Lloret \& Ortega, 2014). González-Lloret and Ortega propose the following criteria for technology-mediated tasks:

- The focus must be on meaning (such as semantic or pragmatic meaning) rather than on form;

- Tasks must have a communicative purpose that is oriented to the learners' goals (i.e., while the use of desired language is required within the task, it is not itself the goal of the task);

- Tasks must be learner-centric and allow learners to use their existing linguistic and non-linguistic resources as well as their digital literacy skills, and must be authentic and reflective of real-world experiences; and

- Learners must be given the opportunity to learn by doing as well as the opportunity to reflect on the process.

A technology-mediated TBLT framework has been found to support and facilitate language acquisition, and the use of such a framework has been found to be as effective as a face-to-face learning environment. (Grgurovic et al., 2013; Lai \& Li, 2011; Lamb, 2004; Ziegler, 2016). In a meta-analysis reviewing the relationship between TBLT and CALL, Lai and Li questioned whether the use of technology-mediated TBLT can enhance learning. They describe a reciprocal relationship between TBLT and CALL: applying a task-based framework can improve the use of CALL, while the addition of technology can enhance a task-based curriculum. Furthermore, they concluded that using said approach may allow for the increased activation of cognitive, behavioural, attitudinal, and social mechanisms. Ziegler (2016) observed that technology-mediated TBLT can improve learner engagement and lower learner anxiety as learners feel more in control of their learning, therefore feeling less pressure to avoid making mistakes. Furthermore, she reported that the use of online multimodal tasks with "visual features" (p.138) led to increased opportunities for learners to use more complex, as well as a wider variety of, pragmatic strategies than in face-to-face interactions alone. This was found to be especially true when video was used as part of the task. 
In contrast with face-to-face learning, Lai and $\mathrm{Li}$ (2011) and Ziegler (2016) found that simpler tasks were more effective than complex tasks. They suggest that the reason for this is due to the technology itself. They propose that the use of CALL media innately makes online tasks more complex compared to face-to-face tasks, as learners are required to make use of their digital literacy skills in addition to their linguistic skills to interact with the task. They advise researchers to keep this in mind when applying a technologymediated TBLT framework. In terms of simplifying tasks for CALL, Ziegler (2016) suggests that focus be on how the implementation of the task addresses the needs and goals of the learners and provides opportunities for learning.

Ziegler's (2016) note about focusing on how tasks address the goals of learners alludes to the use of needs analysis. Needs analysis has been described as a critical first step in developing a task-based curriculum (Long, 2005). This continues to be the case when using a technology-mediated TBLT framework; however, the application of needs analysis must be expanded to account for the use of technology (González-Lloret, 2014).

\section{Needs Analysis and Technology-Mediated TBLT}

Needs analysis allows for the assessment of needs specific to a learner and/or context of learning; its importance in a task-based approach cannot be overstated (Long, 2015). Long states that the ultimate outcome of the needs analysis is to feed task development. A needs analysis can be done in a variety of ways. Long (2005) describes the importance of exploring the context of learning to identify what language is needed for learners to communicate in said context. He observes that the results of most needs analyses resemble a sort of list of "decontextualized structural items" (p. 23) that lend themselves to being input for task design. The importance of needs analysis is explored by Benesch (1996), who emphasizes that to omit needs analysis when developing materials is to narrow learner capabilities by adapting the learner to fit a particular form; the use of needs analysis ensures that focus remains on the learners and their goals. Long (2005) also condemns omitting needs analysis, stating that if such analysis is not done, language learning becomes "one type fits all", therefore lacking the specificity to address language needed for a given context, such as the workplace.

The use of needs analysis as part of the development of a technology-mediated, task-based curriculum has mainly been explored by González-Lloret (2014). GonzálezLloret builds upon Long's (2005) explanation of needs analysis, suggesting that researchers and practitioners expand their analysis to not only learners' linguistic needs but also to their technological requirements and abilities. Like Long, she stresses the use of needs analysis as the first step in developing a task-based CALL module. To do so, González-Lloret recommends assessing the technology itself prior to implementing it in the L2 classroom. This kind of needs analysis explores the appropriateness and suitability of a given technology for the curriculum. This is an analysis of technology capabilities and affordances that considers what training and experience learners and teachers need to have in order to use the chosen tools successfully, including both their linguistic and digital literacy skills (González-Lloret, 2014).

With the understanding that the group of learners participating in this investigation have needs that are not currently being met, this study attempts to explore how their linguistic goals can be fulfilled through the development, implementation, and testing of an 
online module as part of a blended curriculum. Current research speaks to the advantages of the use of technology-mediated TBLT in blended learning contexts, and the importance of considering the context of the learner and the learner's needs prior to determining the technology to be used has been emphasized (Colpaert, 2004).

Using the established needs (i.e., outside-the-classroom, flexible workplace language learning) and abilities (i.e., strong digital literacies), this approach seeks to gain both learner and teacher perspectives and insight on the module developed in order to explore whether the module and adopted approach (i.e., the use of MALL with a TBLT framework) are appropriately offering and delivering services that provide support to this group of learners. Because the development of the module is intended to provide the volunteer teachers with additional support and guidance for their in-person one-on-one sessions, the teachers are considered and included in this study in addition to the learners.

Bearing in mind the literature and the unique context for this study, the following research questions will be addressed:

1. What are the linguistic and technological needs of learners engaged in occupationspecific language training?

2. Can these needs be effectively incorporated into a technology-mediated TBLTbased module?

3. What is the perceived effectiveness of the module by teachers and learners in the occupation-specific language training program?

\section{Methodology}

To address these goals, the study adopted a three-tier approach that included (1) identification of the needs that this group of learners brought to the task of L2 learning through needs analysis, (2) designing the module, and (3) testing its effectiveness. This approach was followed in order to help tailor the module to the learners' goals and needs. Furthermore, this three-tiered approach guided the entire sequence of the design, with the preceding tiers feeding directly into the subsequent tiers. First, a needs analysis was conducted to determine the module's linguistic content and to assist with selecting an appropriate online platform to host said content. The overall design of the module was then done using the outcomes of the needs analysis (i.e., using the linguistic themes revealed to be relevant to this group of learners during needs analysis) and applying the TBLT structure to materials on the module platform. The remaining step of testing the module's effectiveness allowed for insight into learner and teacher perceptions of the module and helped determine the usefulness of the module contents to this group of participants. Before addressing these steps in detail, however, it is important to understand who the participants of this study were.

\section{Participants}

A total of eight participants were involved in this study. They all were associated with the employment support program and were recruited by the program facilitator. Participants were classified as language learners (newcomers needing workplace language 
support, $n=4$ ) and volunteer teachers (volunteers who provide workplace language support, $n=4)$.

Participants in the language learner group were all enrolled in the employment support program. The four participants had been employed through this program, and at the time of this study were working in the customer service sector at various grocery stores. Three of the four participants were receiving ongoing weekly individualized workplace language training from an assigned volunteer teacher. However, one participant was not receiving any language training from the program but reported having had some English language training in the past. The participants spoke Arabic as their first language and were all refugees (one from Syria, and three from Iraq) who, at the time of the piloting and interviews, had been in Canada for less than a year. The employment support program considered the learners to have a Canadian Language Benchmark (CLB) between levels 3 and 5 upon entering the program. Specifically, the program considered two learners as being a level 3 , one as a level 4 , and one as a level 5 . According to the CLB, at the highbeginner/low-intermediate level of proficiency, the learners are expected to understand keywords and formulaic phrases, follow speech at a normal rate in non-demanding situations and produce simple sentences about their everyday wants and needs. Learners at this level may require assistance including repetition and paraphrasing and may depend on the presence of contextual cues in the input (Centre for Canadian Language Benchmarks [CCLB], 2012).

The learners participating in the employment support program are newcomers working in customer service, and as such, need language training focused on the specific language used in the customer service sector (in this context, customer service refers to employment in which an individual regularly interacts face-to-face with customers in such positions as a cashier or handing out food samples at a grocery store). Because these individuals often have varying schedules due to the shift nature of their work and are also burdened with additional personal and family commitments, they face the challenges described by Shaffir and Satzewich (2010) and are not easily able to attend regularly scheduled face-to-face classes. To mitigate this challenge, the application of CALL, or more specifically MALL, was deemed well-suited to the context of this study. This is because MALL is not only flexible, portable, and convenient, but also a questionnaire given to the participants at the program intake revealed that all learners owned and had access to mobile devices (as opposed to computers), which they knew how to use and preferred using.

The teacher participants were all volunteers with the employment support program. As part of their volunteer agreement, each volunteer teacher was paired with a language learner and was expected to meet with the learner weekly for three hours over a threemonth period. The background of each volunteer participant varied. Three of the volunteer teachers were native speakers of English, while one reported Turkish as his mother tongue, with English being his L2. Teaching and employment experience also varied between the volunteer teachers: one was fully certified by TESL Canada as an English as L2 teacher, two had previously taught English in foreign language contexts, and the remaining volunteer teacher had no previous teaching experience (L2 or otherwise) prior to volunteering with the employment support program. The teachers providing weekly language training sessions were volunteers, who, like the learners, also had additional commitments related to work or family. 


\section{Needs Analysis}

González-Lloret (2014) discusses the importance of completing a needs analysis when using technology for language learning and describes what a needs analysis should include. As mentioned previously, traditionally, needs analysis allows for the identification of goals and communicative needs, which, in turn, enables appropriate material design and delivery (Long, 2015). The outcome of the needs analysis is to feed task development. González-Lloret builds on this concept for CALL and adds that a second kind of needs analysis that explores the appropriateness and suitability of the technology for the curriculum is also needed. This is an analysis of technology capabilities and affordances that considers what training and experience learners and teachers need to have in order to successfully use the chosen tools (González-Lloret, 2014). Hence, to develop a module that is in line with the linguistic and technological needs of the participating L2 learners, two types of needs analysis were conducted. The first needs analysis focused on the language and involved (1) a scan of published instructional materials for the workplace, and (2) observations in the workplace. The second analysis emphasized the role of technology and included an examination of the currently available online learning platforms with the goal of choosing the one that best suited the target context.

\section{Linguistic Needs Analysis}

An environmental scan was employed as a method to collect linguistic data, pertaining to customer service, to identify language that is used within the workplace most often, and to ensure that the language to be used within the module would be authentic in content and representation. Furthermore, the environmental scan aided in selecting the topic for the module (the most recurrent type of language was selected to be the theme of the module since it was the first, pilot module in a 10-module program). The use of authentic materials can help connect learning materials to the real world and provide learners with more meaningful exposure to the language (Tomlinson, 2012). Authentic language is a key factor of task-based language learning (Willis \& Willis, 2007), and it was therefore important that the language used within the module be accurately reflective of language used in customer service.

The first component of the environmental scan involved scanning existing workplace language resources to identify and extract language used in the workplace. This was done by examining a total of 14 workplace language textbooks and online workplace language resources. These 14 resources are freely and readily available in Canada and are likely to be used by those wanting workplace language content, including the volunteer teachers with limited or no L2 teaching background. These online resources consisted of resources created by various Canadian colleges and the Canadian government with the intention of providing workplace language support to newcomers. It should be noted that not all of these resources focused on the selected domain of customer service, but all were focused on workplace language. A complete list of materials and resources scanned can be seen in Appendix A. The resources scanned include both the physical textbooks (e.g., the Interface Canada Series, 2007, and the online resources from Norquest College, 2010, 2018, and Bow Valley College, 2018). The Interface Canada Series, for example, has been designed to provide workplace language support with a focus on listening and speaking 
skills. While the early books in the series are designed for lower-intermediate level learners, the later volumes were written for upper-intermediate learners (Government of Canada, 2018). The online resources were published in partnership with the Alberta Open Education Resources and provide support for learners with a Canadian Language Benchmark of 5 to 6 . They are designed using a four skills approach (reading, writing, listening and speaking) and include thematic units focused on topics relevant to the needs of Canadian newcomers (Bow Valley College, 2015).

The second component of the environmental scan involved observing employees working in customer service in the workplace. Observing the environment allows for a more realistic picture of what is happening in the given domain (Long, 2005). A total of three workplace observations (each lasting a total of 3 hours) were conducted, during which a total of five customer service employees were observed at their place of work. Four of the employees were L2 learners participating in the employment support program. Three of these individuals were employed as cashiers in a bakery, while one was employed to hand out food samples at a grocery store. The fifth employee was a native English speaker and was also responsible for handing out food samples. This allowed for a more direct comparison of the similarities and differences used by a non-native and native speaker with the exact same job. During these observations, field notes on the language used were taken.

\section{Technology Needs Analysis}

As part of the technology needs analysis, various online platforms were explored in order to find one best suited to hosting the module. Chapelle (2001) suggests that the following are considered when evaluating a CALL platform: (1) the specific learning situation, (2) the pedagogical approach, and (3) the language learning potential of the software. These criteria were further considered by Hubbard (2006), who adapted them to include considerations of learner fit as well as the practicality and positive impact of the software or platform. It was necessary that the chosen platform address the learners' technological requirements (i.e., it had to be adaptable for use on a mobile device) and be able to host materials in a manner that followed the proposed TBLT framework. Intake information provided by the employment support program showed that its clients prefer to use mobile devices, the preference for which has been reported in research (KukulskaHulme, 2007). The portable and accessible nature of mobile learning was also considered to be well-suited to the needs of the learners. With this in mind, the scope of platforms and software considered as a host for the module excluded those not accessible via a mobile device. With regards to the pedagogical approach, a technology-mediated TBLT approach was desired, which meant that the platform needed to be able to host materials in a manner that allowed for negotiation of meaning, were goal-oriented, authentic, and real-world based (Ziegler, 2016). Therefore, a platform that is available as a mobile app and is highly customizable was identified as necessary to host the module. 


\section{Designing the Module}

The real-world based, authentic and goals-oriented characteristics of TBLT were factors in the decision to follow a task-based framework. Various steps were taken to ensure that the designed module spoke to the TBLT goals in general while adhering to the capabilities of the particular technology. These capabilities include (1) activation of cognitive, behavioural, attitudinal and social mechanisms, (2) improvement in oral proficiency, pragmatic development, comprehension and cultural understanding, (3) learner engagement and individualized learning (Yanguas, 2012). With these in mind, the module aimed to incorporate tasks that allowed for contextualization, language practice, and prediction. The contextualization tasks allowed learners to use behavioural and social mechanisms in order to understand cultural behaviours in customer service. This directly connected with the language practice and production elements of the module, which relied on the activated cognitive mechanisms from the contextualization portion of the module. The language practice tasks built on this knowledge and allowed learners to gain linguistic input while completing tasks that developed comprehension, oral proficiency, and pragmatic awareness. Finally, the prediction portion of the module brought together the contextualization and language practice portions of the module. Learners were required to use the knowledge from these sections and apply it in a more demanding capacity. Opportunities for language production and comprehension were provided, resulting in further activation of the learners' cognitive mechanisms. Together, these components were designed to encourage learner engagement and individualized learning as they worked on the module. Learners maintained control throughout the module, and while the overall structure of the tasks was designed to guide learners, learners were able to control how and when they interacted with the module.

\section{Piloting the Module}

Upon completion of the module, both the learners and their teachers were invited to pilot the tasks within the module and to share their thoughts in a one-on-one interview with the research team.

The completed module consisted of two portions: a greetings portion followed but a requests portion. Participants were given access to the module on a mobile device and asked to complete it. They were not given instruction on the use of the module in order to determine how intuitive the chosen online platform was to use. Following the development of the full module (i.e., the full greetings and requests module), participants were asked to evaluate the updated module. During piloting, participants were given unlimited time to complete the module.

The interviews were conducted following piloting of the module. Interviews were single-session and were semi-structured in nature. By using a semi-structured approach, there was flexibility in the overall format of the interviews, allowing for open-ended discussion (Dörnyei, 2007). The use of interviews to obtain feedback regarding the use of CALL has also been suggested by González-Lloret (2014), who notes that interviews are an effective way to obtain feedback regarding the use of a given technology. Each interview was approximately 45 minutes long. Participants were asked questions regarding their thoughts and perceptions of the module ("What did you like about the module?", 
"What would you change about the module?"), including their opinions on the chosen online platform ("Was software easy to use?"); they were also invited to contribute and discuss any other elements of interest or observations that they had made during the piloting stage. The full interview guide can be seen in Appendix B. During the interviews, extensive notes were taken to document participant responses. Following completion of the interviews, participant responses were analyzed to identify recurring themes. Upon completion of this analysis, certain feedback and comments were found to have been made by multiple participants. The results of this analysis will be discussed below.

\section{Results and Discussion}

\section{Needs Analysis}

\section{Linguistic Needs Analysis}

The scan of the textbooks and online resources along with the in-person observations provided evidence that greetings and requests proved to be the most used in everyday interactions within the customer service sector (see Tables 1 and 2 for examples of greetings and requests found during the environmental scan of textbooks and online resources). Hence, both themes were selected for the module. However, because "requests" is a very broad category, it needed to be narrowed for scope. To this end, it was decided that requests would be limited to what Long (1983) refers to as requests to negotiate meaning. These requests can be used to help learners during communication breakdowns (Cook, 2015) and allow them to assess whether or not they have been successful at communicating with native/proficient speakers (Long, 1983). There are three different types of requests within this category. These are referred to by Long as requests for clarification ("What do you mean?), requests for confirmation ("You want this one?), and comprehension checks, also known as repetition ("You want ?"). These requests allow the learner to receive additional linguistic information and input and can help prevent communication breakdowns (Cook, 2015). The use of the requests was especially useful for the proficiency level of the target learners as they would allow them to effectively seek assistance in the form of repetition, further explanation, or rewording to ensure understanding (CCLB, 2012).

\section{Table 1}

Most Frequent Greetings found in Textbooks and Online Resources

\begin{tabular}{lc}
\hline Greetings & Number of Occurrences \\
\hline Hello. & 65 \\
\hline Hi. & 48 \\
\hline Hello, what can I do for you? & 12 \\
\hline Bye! & 12 \\
\hline Hi there! & 10 \\
\hline
\end{tabular}


Table 2

Most Frequent Requests found in Textbooks and Online Resources

\begin{tabular}{lc}
\hline Requests & Number of Occurrences \\
\hline I'm sorry, I don't understand. & 10 \\
\hline What did you say? & 8 \\
\hline I'm not sure about... & 6 \\
\hline Would it be possible for you to repeat that? & 6 \\
\hline Can you say that again? & 6 \\
\hline
\end{tabular}

\section{Technology Needs Analysis}

It was important to select a platform that was easy to use and available on mobile devices. Levy and Stockwell (2006) emphasize the importance of choosing a platform that is not only suited to the language needs of the learners but is also capable of hosting materials that will allow learners to achieve their language goals. Bearing this in mind, and considering the needs of the learners, the e-learning software Moodle was selected as it fulfilled these criteria. Moodle is an open-source, freely available software that allows for learning on mobile devices (Costello, 2014). It is highly customizable, which was beneficial from a pedagogical perspective as this meant that it was possible to incorporate materials into the module that followed the desired pedagogical framework (i.e., technology-mediated TBLT). Furthermore, Moodle is designed to be used for blended learning (i.e., to support rather than replace face-to-face learning) and has previously been praised for being user-friendly (Horvat et al., 2012). With regards to using Moodle on a mobile device, an app can be downloaded and installed directly onto a mobile device, and within this app, the module can be downloaded. During the piloting of the module, participants were able to use this mobile Moodle app to test the module with ease. Additionally, Moodle's affordance to have users download modules within the app means that learners can use their mobile device for learning in environments where there is no internet access.

\section{Designing the Module}

Based on the analysis of the affordances associated with the technology-mediated TBLT framework, it was deemed necessary for the module to include tasks that allowed for contextualization, language practice, and prediction opportunities. The tasks developed for the module require learners to use their existing linguistic resources and knowledge and to draw on their real-world (i.e., their workplace) experiences. As the module progresses, the tasks within the module become more challenging and require the learner to use knowledge they have had access to during previous tasks. Furthermore, the previously completed analysis ensured that all language used within the module was authentic and relevant to this specific group of learners (i.e., customer service workers). The module is specifically designed to address the workplace goals of this group of learners. This aligns with the criteria for applying a technology-mediated TBLT framework proposed by Gonzalés-Lloret and Ortega (2014).

Since contextualization has been considered to be a strength of TBLT (Beglar \& Hunt, 2002), a contextualizing component was included to allow for scaffolding and 
schema building (Gonulal \& Loewen, 2018) which will help learners to complete the remaining portions of the module. To contextualize the language of the module (for both greetings and requests portions), learners were first asked to watch a video of an interaction between a customer service representative and a customer. Following the video, they answered a series of multiple-choice questions regarding the context and interaction depicted in the video (e.g., "Who are the people in the video?"). It should be noted that the videos currently used in the module are pilot videos, hence the rough set, and low quality. These videos will be replaced with professional videos that will use a proper set and that will be filmed with professional filming equipment (participants were made aware of this during piloting). Figure 1 provides an example from the greetings portion of the video, where the learners can see a customer service representative greet two different customers. The video models these interactions for the learners, allowing them to use cues within the video to identify the setting, people and purpose of language featured in the video. The follow-up questions guided and helped to reinforce the context for the learners.

\section{Figure 1}

\section{Example of a Contextualization Question}

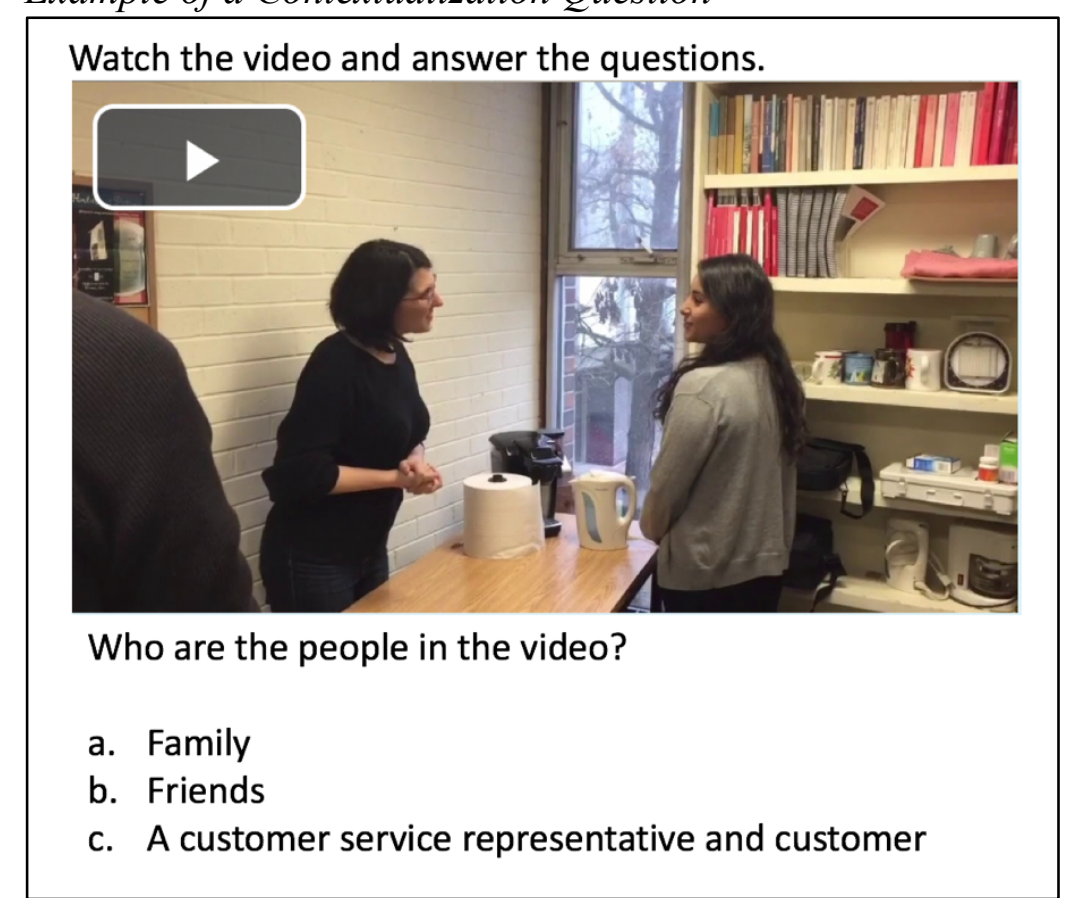

Following the contextualizing questions, the learners were asked to watch the same video again, but this time, learner attention was drawn to the language used in the video. Specifically, the learner was asked to focus on the responses provided by the customer in the scenario to highlight the type of language typical in such interactions. As Figure 2 shows, a learner is asked to type in a response to the "What did the customer service representative say to greet the customer?" question. Following this, learners would continue their language practice by watching more videos of interactions between customer service representatives and customers and matching each video to a short summary or description of the video contents. For example, a video in which a customer service 
representative says: "Thank you. Have a good night" to a customer could be matched with this description: "The customer service representative finishes helping a customer."

Figure 2

Example of Language Practice

Watch the video and answer the questions.

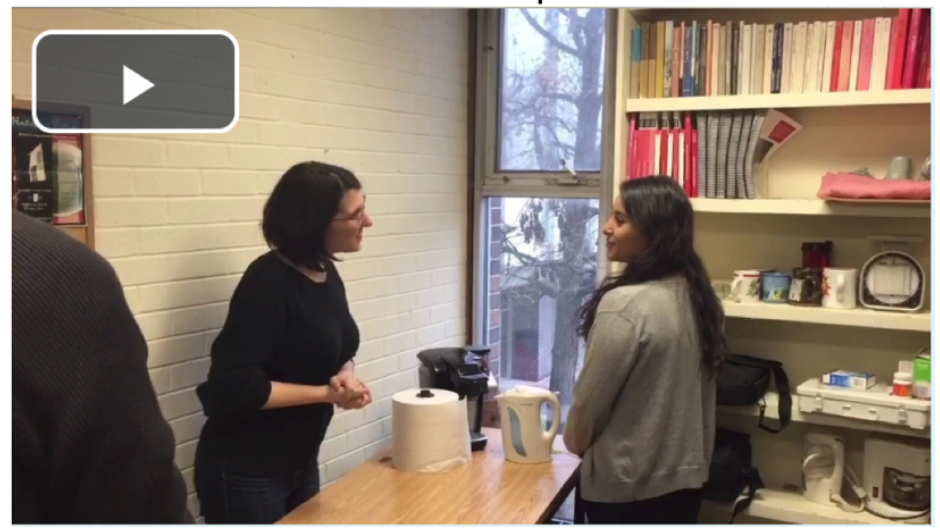

How does the customer service representative say hello?

The next part of the module involves learners applying the language they had been exposed to in the module up to that point. Two types of tasks were used for the prediction phase of the module. For the first task type, learners watched videos of incomplete interactions between a customer service representative and a customer and were asked to predict what could happen next. For example, one of the videos includes an interaction between a customer service representative and a customer in which they are interrupted by another customer. After watching the video, the learner is asked: "What could the customer service representative say next?" and is invited to type in an answer in the provided space. It is important to note that in designing this task, we knew that there could not be just one answer to this question and that multiple correct answers could be provided by the learner. This meant that extra consideration needed to be made in terms of the feedback that learners would receive upon submitting their answer. Specifically, in order to avoid prescribing one correct answer, learners were provided with an example of a possible response and were then advised to discuss their original answer with their teacher (Figure 3 ). In addition to avoiding prescribing only one answer, this consideration helped connect the online modules to the face-to-face sessions with the volunteer teachers as part of a blended curriculum. Volunteer teachers could review the learner's answers to the prediction tasks and use them to guide the face-to-face session. For example, if a learner provided an answer that was grammatically incorrect, the session could focus on the correct grammatical form, or if the answer was pragmatically inappropriate, the session could discuss why this answer was not suitable for the situation. Even if the learner's answer was accurate, it could still be used to guide a discussion of other possible response options. 


\section{Figure 3}

Prediction Task Feedback

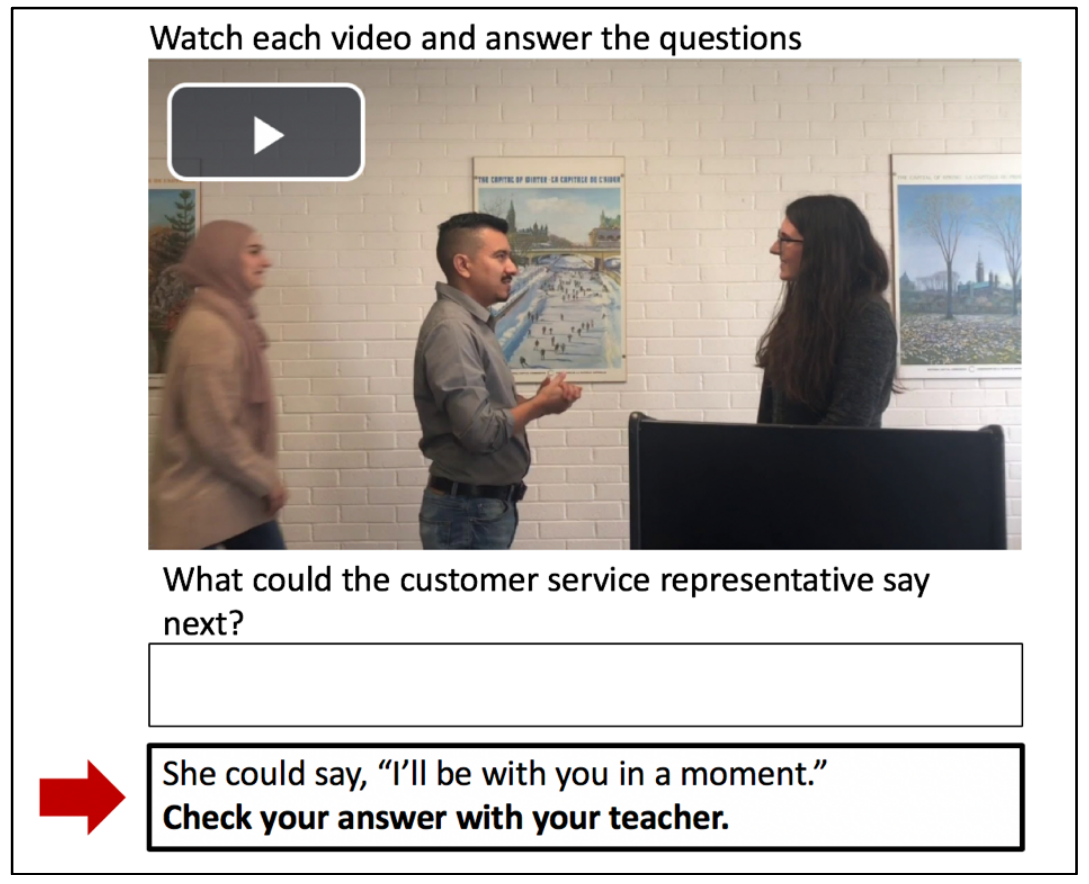

The second task type consisted of scenario-based questions that combined language practice with learners assessing a situation and predicting what could happen next.

Learners were provided with a dialogue of a situation, in which there was a communication breakdown between a customer service representative and a customer and were then asked to (1) identify what language the customer service representative used to try and overcome this breakdown and (2) to assess the effectiveness of the response. Following this, learners were asked to predict what could be said next by the customer service representative. This allowed the learners to apply the input they received in the earlier parts of the module and apply it to new situations with increased cognitive demands. Like the first type of tasks, learners were provided with a suggested answer in the feedback and were again told to check the appropriateness and/or accuracy of the response with their teacher. Figure 4 illustrates a scenario question. These questions were the most complex in the module and were presented last to ensure the learners were prepared for the demands of the task (Mackey et al., 2016) as well as to allow them to apply the language and knowledge that they had already interacted with earlier in the module to new situations (Schulze \& Liebscher, 2010). 


\section{Figure 4}

Scenario-Based Questions

A customer asks Sarah for a tea, but Sarah doesn't understand.

Sarah: $\mathrm{Hi}$, how can I help you?

Customer: Can I have an English breakfast tea?

Sarah: Do you want a breakfast sandwich?

Customer: No. I want a tea.

1. What does Sarah say to check if she understands?

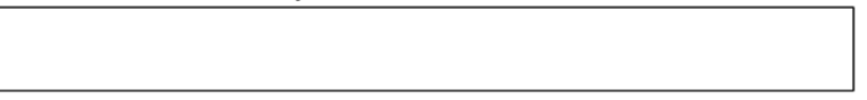

2. Did saying this help Sarah?

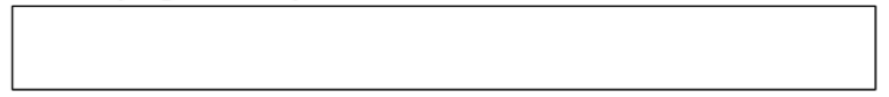

3. What should Sarah say next?

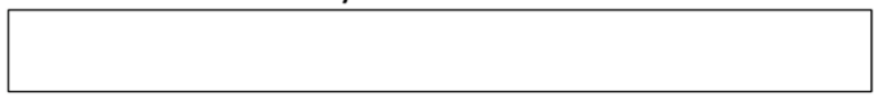

\section{Testing the Module}

The feedback received from the learners and volunteer teachers during the interviews was overall positive. Feedback was obtained regarding both the module design and usability. In terms of usability, all the learners and volunteer teachers declared the module easy to use. Similar to past studies that explored the usability of Moodle (e.g., Horvat et al., 2012), the participants found the platform's interface to be clear and straightforward.

The language content of the module was also well-received by the learners and volunteer teachers. All four learners stated that the language used within the module was an accurate representation of the language that is used in their places of work. Three of the volunteer teachers who had previous work experience in customer service also indicated that they found the language to be reflective of language used in the customer service sector.

The language in the videos was also highly appreciated. The inclusion of videos was considered positive by all participants, and all four volunteer teachers positively commented on the video dialogue. They considered the dialogue to be authentic and relevant to customer service and easy to follow. One of the volunteer teachers with experience in L2 teaching and material development commented on the pacing and use of contractions within the video. She observed that the pacing matched regular speech and was not slowed down for the learners; she also appreciated that contractions were maintained rather than omitted. She felt that this was a change from other teaching materials she had used in the past and praised this inclusion as increasing the authenticity of the language used for the interactions in the videos, specifically stating that the video content accurately represented interactions between customer service representatives and customers. 
The phrasing used for the questions that follow the videos was considered by learners to be clear and easy to understand. Two of the volunteer teachers also indicated that they felt the wording of the questions would be easy for the learners to follow and that the questions were appropriate for the proficiency levels of the learners. The proficiency of the learners was also discussed with regard to the length of the module. The module took 45 to 60 minutes to complete with the completion time varying from learner to learner; higher-level learners generally took less time to complete the module than did their lowerlevel peers. At times, these learners would watch the videos a second time before answering the questions or to confirm their answer. All four learners felt the length of the module was appropriate. Only one volunteer teacher commented on the length of the module, saying that she liked the length of the module and that she would not make it any longer. She indicated that while she would complete a module that was this length, she would not likely complete the module if it was any longer. Lastly, the four learners stated that they would use the module for workplace language training.

However, the participants also made suggestions on how to improve the design of the module and the type of additional content to include. Recurring suggestions included: (1) improving the overall video quality, (2) modifying the feedback timing for the multiple-choice question, and (3) adding a pronunciation component.

With regard to the video quality, it should be noted that the videos included in the module and viewed by participants during the piloting were intended to be placeholders. The incorporation of videos has been noted to be one of the benefits of using technology for language learning (Guichon \& McLornan, 2008), and as such, they were included in the module design. However, one of the important aspects of this study was obtaining feedback from L2 learners and volunteer teachers, and their feedback on the videos was desired prior to producing finalized videos. As the feedback regarding the content of the videos was positive, there are now plans to recreate the placeholder videos using higherquality equipment. In particular, the audio quality was noted as low by both learners and volunteer teachers, who worried that it would be challenging to hear the language used in the videos in nosier public settings. As one of the noted advantages of developing the module using a mobile device is the ability to use the module anytime and anywhere, the new videos will need to have high enough audio quality to be used in various settings.

The second suggestion made by both learners and the volunteer teachers was that the timing of feedback for the module's multiple-choice questions should be modified. In a testing setting ${ }^{1}$, Moodle does not allow learners to receive feedback on the module questions until the end of the entire module has been completed and submitted. However, Moodle allows learners to receive feedback on the multiple-choice questions individually; each time a learner answers a multiple-choice question, they are given feedback about that question. During the piloting of the module, the feedback set-up for multiple-choice questions followed the latter format. Both learners and volunteer teachers felt that this was confusing and that it negatively impacted the flow of the module. One learner who had answered a multiple-choice question incorrectly thought that this feedback was a result of his incorrect answer and thought that this meant he was unable to progress in the module. Obtaining feedback after each question meant that the flow from question to question was inconsistent. Because of this, a more advanced version of Moodle will be employed which allows for more customization allowing for the timing of the feedback for multiple-choice questions to be modified. ${ }^{2}$ 
The final suggestions concerned the fact that there were no explicit opportunities for pronunciation practice within the module. This was of particular concern to the learners, with three of the four learners stating that they needed help improving their pronunciation, and thus would like a pronunciation component to be added to the module. To fulfill this request, existing online pronunciation tools have been incorporated into the module as resources for learners. These pronunciation tools are YouGlish (YouGlish, n.d.) and English Accent Coach (Thompson, 2012). YouGlish allows learners to search for English words or phrases, which they can then hear being pronounced. This is done through a connection with YouTube, and all words and phrases are presented to the learner as a YouTube video. YouGlish aims to provide language that is spoken in the real world in context (YouGlish, n.d.). English Accent Coach allows learners to practice their pronunciation of English consonants and vowels through brief lessons on the International Phonetic Alphabet (IPA) and through online games. English Accent Coach has been developed using pronunciation teaching research, and, like the module developed here, is meant to be used as a supplement, rather than replacement, to face-to-face learning (Thompson, 2012).

\section{Conclusion, Pedagogical Implications, and Future Research Directions}

This paper described the development of an online module that focused on the greetings and requests used in customer service. It was intended to be the first of 10 modules aiming to provide occupation-specific language training for newcomers working in the customer service sector. The module was designed in line with the recommendations put forth by technology-mediated TBLT scholars. These included: application of needs analysis that determines both language and technological needs, adoption of the TBLT framework in task design, authentic language use, and consultation with the end-users (learners and their teachers) during the design process. While the positive feedback obtained from the participants validates the adopted pedagogical approach and the use of technology to support its implementation, the application of needs analysis helped ensure that the language used was authentic and reflective of the language used in customer service. Furthermore, learner feedback obtained during the module preparation not only ensured that the module contents addressed the needs and desires of the learners it was designed to serve, but that this consultation also allowed the learners to play an active role in their own learning, and in doing so helped to promote learner autonomy that can lead to learner independence and empowerment (Fleming \& Walter, 2004).

The participating volunteer teachers can, too, benefit from using this module as a way to supplement their face-to-face sessions and to guide the learning of the students they are working with. The latter point is especially poignant in light of these volunteer teachers not necessarily having language teaching training and/or experience. This module can be used by the teachers to help guide their sessions, providing support not only for the learners but also for the teachers themselves. The teachers will be able to view areas that learners may find more challenging and in which they need more support. Long (2005) suggests that while learners should be consulted regarding their linguistic needs, they may not always be able to identify or be aware of some of the challenges they face. Using technology-enabled module statistics, volunteer teachers can review the learners' answers to determine areas that learners need to work on without having to rely on learner 
awareness of areas in which they need continued practice. An example of this became apparent during the module testing process, in which one volunteer teacher became aware that the learner she was paired with incorrectly used the pronoun "I" and made a note to review this with him in future sessions.

The successful design and implementation of a structure for the module will be used in the development of subsequent modules aiming to provide further workplace language support for newcomers enrolled in the employment support program. These future modules can use the pedagogical approach adopted in the development of this first module while varying the theme from module to module. Further application of needs analysis and the environmental scan can be used to aid in the selection of themes and in determining the language to populate the remaining modules.

This work has also identified opportunities for additional applied linguistics research. For example, the work conducted in the environmental scan could continue and lead to the development of a customer service language corpus that could be accessed by teachers wanting to develop authentic materials to use with learners working in customer service. Learners can continue to be consulted throughout this process and could be consulted as the development of the future modules progresses.

Future research could also explore the learners' attitudes and beliefs regarding the module use on a long-term basis, similar to research conducted by Ushioda (2013) which explores the motivational impact of technology on language learning. This could include exploring whether or not learners' motivation regarding language learning increases with the use of the module and how this relates to their experiences in the Canadian workforce.

Overall, the completed module is theory-driven, and learner, teacher, and program approved. The application of theory combined with the piloting and assessment of the module from learners and volunteer teachers strengthens the overall integrity of the module design. The module is designed to address the learners' workplace language goals and has been designed using a TBLT framework that incorporates authentic workplace language that prepares learners to use greetings and requests in the workplace. The module is intended to be used as part of a blended program that has some face-to-face learning. A blended approach allows learners to make use of the online platform at their convenience, but also allows learners to receive additional support and guidance in a face-to-face environment while still providing. For example, while the online module allows learners to receive some instant feedback regarding their mistakes and errors, additional and more comprehensive feedback can be provided by teachers during the face-to-face sessions. Overall, the findings of the study highlight the benefits of the adopted pedagogical approach, which has implications for the implementation and development of subsequent modules designed to provide outside the classroom support to newcomers. In addition to the pedagogical implications, there are research implications that can be explored as this project continues to expand and grow.

Correspondence should be addressed to Gillian McLellan.

Email: gillianmmclellan@cmail.carleton.ca 


\section{Notes}

${ }^{1}$ The version of Moodle used to host the module necessitated the use of Moodle's "quiz" tool. This tool is somewhat limited in a number of ways including the ability to provide formative feedback.

2 This version of Moodle includes a "lesson plan" tool that offers a greater number of features and fewer limitations compared to the "quiz" tool.

\section{References}

Ally, M., McGreal, R., Schafer, S., Tin, T. \& Cheung, B. (2007). Use of mobile learning technology to train ESL adults. Proceedings of the Sixth International Conference on Mobile Learning, Melbourne. http://hdl.handle.net/2149/2582

Beglar, D. \& Hunt, A. (2002). Implementing task-based language teaching. In J.C. Richards \& W.A. Renandya (Eds.). Methodology in language teaching: An anthology in current practice. (pp.96-106). Cambridge University Press.

Blake, R., Wilson, N.L., Cetto, M. \& Pardo-Ballester, C. (2008). Measuring oral proficiency in distance, face-to-face, and blended classrooms. Language Learning \& Technology, 12(3), 114-27. http://dx.doi.org/10125/44158

Blake, R. J. (2013). Brave new digital classroom: Technology and foreign language learning. Georgetown University Press.

Bow Valley College. (2015). OER creation for ELL. https://globalaccess.bowvalleycollege.ca/research-development/projectsdevelopment/oer-creation-ell

Centre for Canadian Language Benchmarks. (2012). Canadian language benchmarks: English as a second language for adults. Ottawa: Ministry of Citizenship and Immigration.

https://www.canada.ca/content/dam/ircc/migration/ircc/english/pdf/pub/languagebenchmarks.pdf

Chapelle, C. (2001). Computer applications in second language acquisition: Foundations for teaching, testing, and research. Cambridge University Press.

Colpaert, J. (2004). From courseware to coursewear?. Computer Assisted Language Learning, 17(3-4), 261-6. https://doi.org/10.1080/0958822042000319575

Cook, J. (2015). Negotiation for meaning and feedback among second language learners. Journal of Language Teaching and Research, 6(2), 250-57. http://dx.doi.org/10.17507/j1tr.0602.02

Costello, E. (2014). Opening up to open source: Looking at how Moodle was adopted in higher education. Open Learning: The Journal of Open, Distance and e-Learning, 28(3), 187-200. https://doi.org/10.1080/02680513.2013.856289

Dörnyei, Z. (2007). Research methods in applied linguistics. Oxford: Oxford University Press.

Farr, F. \& Murray, T. (2016). Introduction. In F. Farr and T. Murray (Eds.), The Routledge handbook of language learning and technology. (pp. 1-5). Routledge. 
Fleming, D. \& Walter, P. (2004). Linking teacher professionalism and learner autonomy through experiential learning and task design [Special issue]. TESL Canada Journal/Revue TESL du Canada, 4, 58-72. https://doi.org/10.18806/tesl.v0i0.1040

Godwin-Jones, R. (2011). Emerging technologies: Mobile apps for language learning. Language Learning and Technology, 15(2), 2-11. http://dx.doi.org/10125/44244

Gonulal, T. \& Loewen, S. (2018). Scaffolding technique. In J.I. Liontas (Ed.). The TESOL encyclopedia of English language teaching. (pp. 1-5). John Wiley \& Sons.

González-Lloret (2014). The need for needs analysis in technology-mediated TBLT. In M. González-Lloret \& L. Ortega (Eds.), Technology-mediated TBLT: Researching technology and tasks. (pp. 23-50). John Benjamins Publishing Company.

González-Lloret, M. \& Ortega, L. (2014). Towards technology-mediated TBLT. In M. González-Lloret \& L. Ortega (Eds.), Technology-mediated TBLT: Researching technology and tasks. (pp. 1-22). John Benjamins Publishing Company.

Government of Canada, (2018). Language learning products catalogue of the Canada school of public service.

http://publications.gc.ca/site/eng/search/LanguageLearningProductsCatalogue.ht $\mathrm{ml}$

Government of Saskatchewan. (2019). Language Training. https://www.saskatchewan.ca/residents/moving-to-saskatchewan/immigrating-tosaskatchewan/language-training-and-settlement-services/language-training

Guichon N. \& McLornan, S. (2008). The effects of multimodality on L2 learners: Implications for CALL resource design. System, 36(1), 85-93. https://doi.org/10.1016/j.system.2007.11.005

Hampel, R. \& Hauck, M. (2004). Towards an effective use of audio conferencing in distance education courses. Language Learning \& Technology, 8(1), 66-82. http://doi.org/10125/25230

Horvat, A., Dobrota, M., Krsmanovic, M., \& Cudanov, M. (2012). Student perception of Moodle learning management system: A satisfaction and significance analysis. Interactive Learning Environments, 23(4), 515-27. https://doi.org/10.1080/10494820.2013.788033

Hubbard, P. (2006). Evaluating CALL Software. In L. Ducate \& N. Arnold (Eds.), Calling on CALL: From theory and research to new directions in foreign language teaching. (pp. 1-26). CALICO Monograph Series.

Immigration, Refugees and Citizenship Canada. (2019). Newcomer services. https://www.canada.ca/en/immigration-refugeescitizenship/campaigns/newcomers.html?utm_campaign=notapplicable\&utm_medium=vanity-url\&utm_source=canada-ca_newcomerservices

Kukulska-Hulme, A. (2007). Mobile usability in educational contexts: What have we learnt?. International Review of Research on Open and Distance Learning, 8(2), 1-16. https://doi.org/10.19173/irrodl.v8i2.356

Kukulska-Hulme, A. \& Shield, L. (2008). An overview of mobile assisted language learning: From content delivery to supported collaboration and interaction. ReCALL, 20(3), 271-89. https://doi.org/10.1017/S0958344008000335

Kustec, S. (2012). The role of migrant labour supply in the Canadian labour market. Ottawa: Citizenship and Immigration Canada. 
https://www.canada.ca/content/dam/ircc/migration/ircc/english/resources/research /2012-migrant/documents/pdf/migrant2012-eng.pdf

Lamb, M. (2004). Integrative motivation in a globalizing world. System, 32(1), 3-19. https://doi.org/10.1016/j.system.2003.04.002

Lai, C. \& Li, G. (2011). Technology and task-based language teaching: A critical review. CALICO Journal, 28(2), 498-521. https://doi.org/ 10.11139/cj.28.2.498-521

Levy, M. \& Stockwell, G. (2006). Theory. CALL Dimensions. (pp. 110-41). Lawrence Erlbaum Associates. Long, 2005

Long, M. (2003). Linguistic and conversational adjustments to non-native speakers. Studies in Second Language Acquisition, 5(2), 177-93. https://doi.org/10.1017/S0272263100004848

Long, M. (2005). Second language needs analysis. Cambridge University Press.

Long, M. (2015). Second language acquisition and task-based language teaching. John Wiley \& Sons.

Mackey, A., Ziegler, N. \& Bryfonski, L. (2016). From SLA research on interaction to TBLT materials. In B. Tomlinson (Ed.). SLA Research and Materials Development for Language Learning. (pp. 103-17). SLA research and materials development for language learning. Routledge.

Murphy, J. (2010). The settlement \& integration needs of immigrants: A literature review. Citizenship and Immigration Canada. https://olip-plio.ca/knowledgebase/wp-content/uploads/2013/03/Olip-Review-of-Literature-Final-EN.pdf

O'Bryan, A. \& Hegelheimer, V. (2007). Integrating CALL into the classroom: The role of podcasting in an ESL listening strategies course. ReCALL, 19(2), 162-80. http://doi.org/10.1017/S0958344007000523

Ontario Council of Agencies Serving Immigrants. (2017). What different kinds of ESL programs are available?. https://settlement.org/ontario/education/english-as-asecond-language-es1/esl-for-adults/what-different-kinds-of-esl-programs-areavailable/

Payne, J. S. \& Whitney, P. J. (2002). Developing L2 oral proficiency through synchronous $\mathrm{CMC}$ : Output, working memory and interlanguage development. CALICO Journal, 20(1), 7-32. http://doi.org/10.1558/cj.v20i1.7-32

Schulze, M. \& Liebscher, G. (2010). Going in cycles: Courseware and material development for written communication. CALICO Journal, 27(3), 554-63. https://doi.org/10.11139/cj.27.3.554-563

Schwienhorst, K. (2008). Learner autonomy and CALL environments. Routledge.

Shaffir, W. \& Satzewich, V. (2010). The informal settlement sector: Broadening the lens to understand newcomer integration in Hamilton. Hamilton Integration Partnership.

Stockwell, G. (2007). A review of technology choice for teaching language skills and areas in the CALL literature. ReCALL, 19(2), 105-120. http://doi.org/10.1017/S0958344007000225

Stockwell, G. (2010). Using mobile phones for vocabulary activities: Examining the effect of the platform. Language Learning and Technology, 14(2), 95-110. http://dx.doi.org/10125/44216 
S.U.C.C.E.S.S. (2019). Immigration Settlement \& Integration Program. https://www.successbc.ca/eng/services/settlement-services/immigrant-settlementintegration-program/\#ccw

Thompson, R. (2012). English Accent Coach. https://www.englishaccentcoach.com/

Tomlinson, B. (2012). Materials development for language learning and teaching. Language Learning, 45(2), 143-79. https://doi.org/10.1017/S0261444811000528

Ushioda, E. (2013). Motivation matters in mobile language learning: A brief commentary. Language Learning and Technology, 17(3), 1-5. http://doi.org/10125/44333

Willis, D., \& Willis, J. (2007). Doing task-based teaching. Oxford University Press.

Yang, J. (2013). Mobile assisted language learning: Review of the recent applications of emerging mobile technologies. English Language Training, 6(7), 19-25. https://doi.org/10.5539/elt.v6n7p19

Yanguas, I. (2012) Task-based oral computer-mediated communication and L2 vocabulary acquisition. CALICO Journal, 29, 507-31. https://doi.org/10.11139/cj.29.3.507-531

YouGlish. (n.d.). https://youglish.com/

Ziegler, N. (2016). Taking technology to task: Technology-mediated TBLT, performance and production. Annual Review of Applied Linguistics, 36, 136-63. https://doi.org/10.1017/S0267190516000039 


\section{Appendix A}

\section{Resources Consulted During Environmental Scan}

\begin{tabular}{|l|l|}
\hline \multicolumn{1}{|c|}{ Resource } & \multicolumn{1}{|c|}{ Publisher } \\
\hline $\begin{array}{l}\text { Here to help: Workplace communication skills for } \\
\text { food services }\end{array}$ & Bow Valley College (2018) \\
\hline $\begin{array}{l}\text { In the workplace: An intermediate integrated } \\
\text { skills textbook }\end{array}$ & Bow Valley College (2018) \\
\hline Interface Canada 1 & Canada School of Public Service (2007) \\
\hline Interface Canada 2 & Canada School of Public Service (2007) \\
\hline Interface Canada 3 & Canada School of Public Service (2007) \\
\hline Interface Canada 4 & Canada School of Public Service (2007) \\
\hline Interface Canada 5 & Canada School of Public Service (2007) \\
\hline Interface Canada 6 & Canada School of Public Service (2007) \\
\hline Interface Canada 7 & Canada School of Public Service (2007) \\
\hline Interface Canada 8 & Canada School of Public Service (2007) \\
\hline $\begin{array}{l}\text { Common ground: Guide to English in the } \\
\text { workplace (Phase 2) }\end{array}$ & Norquest College (2010) \\
\hline $\begin{array}{l}\text { Common ground: Guide to English in the } \\
\text { workplace (Phase 3) }\end{array}$ & Norquest College (2010) \\
\hline LINC works curriculum & Norquest College (2018) \\
\hline Online workplace integration language resources & Norquest College (2018) \\
\hline
\end{tabular}




\section{Appendix B}

\section{Interview Guide}

1. What did you think about the module?

2. What did you think about the software?

3. What did you like about the module?

4. What did you not like about the module?

5. How easy or difficult it was to use?

6. What parts did you find most helpful?

7. What parts did you find least helpful?

8. Is there anything that you would add to the module?

9. Is there anything you would remove from the module?

10. Additional comments/concerns. 